\title{
O ESTADO DE COISAS INCONSTITUCIONAL E A TUTELA DOS DIREITOS HUMANOS FUNDAMENTAIS
}

\author{
Andréa Karla da Silva Alves ${ }^{117}$
}

Recebido em: 01/12/2018

Aprovado em: 27/03/2019

\section{RESUMO}

Técnica desenvolvida pela Corte Constitucional Colombiana chamada de "O Estado de Coisas Inconstitucional", tema novo e pouco estudado, é utilizada em julgamentos quando se verifica a existência de um quadro de vasta violação a direitos humanos fundamentais, causado pela inatividade ou inépcia constante e pertinaz das autoridades públicas em alterar o contexto atual, de maneira que apenas modificações estruturais do exercício do Poder Público e o desempenho de uma diversidade de autoridades são capazes de transformar a situação inconstitucional. Com o Estado de Coisas Inconstitucional uma nova forma de solucionar problemas estruturantes será formada, permitindo-se proferir decisões que criam mecanismos de desimpedimento aos canais de deliberação, visando o controle da organização e da execução das políticas públicas de forma participativa, comprometida de forma geral com a proteção aos direitos sucumbidos. Assim, propõe-se com essa pesquisa uma análise da teoria, seus requisitos e parâmetros para que sejam aplicados na realidade brasileira em situações de violações e inconstitucionalidades aos direitos fundamentais amparados pela Constituição Federal. Para a realização dessa pesquisa foi utilizado o método bibliográfico de caráter qualitativo, o qual foi desenvolvido através da busca sistemática de livros, artigos em periódicos, sites e revistas atuais que tratam da temática além do ordenamento jurídico então vigente. No que tange a metodologia científica de análise, se utilizou dos métodos teórico-descritivos, bem como de uma análise dialética da problemática apresentada.

Palavras-chave: Direitos Humanos Fundamentais. Estado de Coisas Inconstitucional. ADPF n ${ }^{\circ}$ 347. Supremo Tribunal Federal.

\section{INTRODUÇÃO}

\footnotetext{
${ }^{117}$ Mestranda em Direito pela Universidade Federal do Rio Grande do Norte - UFRN. Advogada.
} 
Ao longo dos anos, as nações democráticas passaram a ser regidas por preceitos normativos constitucionais sólidos de legitimidade, racionalidade e justiça. Ocorre que, em alguns cenários institucionais, percebe-se uma negligência quanto à inobservância estatal desses preceitos considerados fundamentais, como o da dignidade da pessoa humana, liberdade e igualdade, não consolidados na prática e que acabam resultando em um "Estado das coisas inconstitucionais".

Adotado primeiramente pela Suprema Corte na colômbia, o instituto do Estado de Coisas Inconstitucional (ECI) teve seu ápice no início da década de 90, quando uma assombrosa crise no sistema penitenciário colombiano foi acompanhada por todo o mundo. Sua declaração se deu pela demasiada violação dos direitos humanos e, ainda, pela inviabilidade da concretude dos direitos fundamentais.

No Brasil, o instituto foi reconhecido recentemente, através da ADPF 347/DF, também pela mesma ocorrência, uma crise no sistema penitenciário brasileiro. A denúncia em síntese tinha por objetivo fazer com que algo fosse efetivado para mudar o quadro atual de caos em que se encontram as penitenciárias brasileiras.

Ao declarar o ECI, a Suprema Corte admite a existência de uma considerável violação aos direitos fundamentais em oposição a um grupo de pessoas fragilizadas e convoca todos os órgãos públicos responsáveis para adotarem medidas eficientes com o objetivo de solucionar tal entrave.

Dessa forma, o instituto prega uma maneira de reconhecer que a atual situação está desordenada e incontrolável, sendo necessário que todos os órgãos responsáveis se comprometam e avoquem para si uma responsabilidade real de deliberar sobre o problema de forma eficaz e eficiente. Isto é, o que se estima é que sejam adotadas medidas e atribuições pelos responsáveis diretos pela situação, conforme suas competências, para que assim o problema seja solucionado.

Portanto, o objetivo dessa pesquisa é demonstrar que a técnica do ECI, caso utilizada, mobilizará todo o aparato institucional brasileiro na busca de diagnósticos de situações geradoras de violações consideráveis aos direitos humanos. Com isso, verificar-se-á que seu caráter estrutural influenciará a elaboração de medidas reparadoras capazes de restabelecer definitivamente a ordem nas mais diversas áreas sociais abandonadas.

A metodologia utilizada para o desenvolvimento desse trabalho foi a teóricodescritiva, expondo o tema em seu estado atual e as suas principais conjunturais e dialética na análise de duas vertentes. Ademais, se utilizou o método bibliográfico de caráter qualitativo, o 
qual foi desenvolvido através da busca sistemática de livros, artigos em periódicos, sites e revistas atuais que tratam da temática além do ordenamento jurídico então vigente.

Conclui-se que, apesar da sua imaturidade, a técnica se demonstra aplicável quando encontradas todas as suas características necessárias para coibir a alarmante inconstitucionalidade que se paira em situações que envolvam os direitos humanos sucumbidos.

\section{EFETIVIDADE DOS DIREITOS HUMANOS E FUNDAMENTAIS}

O progresso, o respeito mútuo dos indivíduos e a cidadania advêm de um longo percurso pelo tempo enfrentado pela humanidade para efetivar e proteger os direitos inerentes a todos, capazes de assegurar uma vida digna resguardada dos abusos de poder praticado pelos Estados. Conforme denota Moraes (2006):

O conjunto institucionalizado de direitos e garantias do ser humano tem por finalidade básica o respeito a sua dignidade, por meio de sua proteção contra o arbítrio do poder estatal e o estabelecimento de condições mínimas de vida e desenvolvimento da personalidade humana ${ }^{118}$.

$\mathrm{Na}$ história do constitucionalismo brasileiro, a Constituição Federal de 1988 é a primeira brasileira a elencar o princípio da prevalência dos direitos humanos como fundamental às relações internacionais do Estado, sendo uma das mais expressivas conquistas nos últimos tempos a garantia de direitos fundamentais aos cidadãos, frente ao próprio Estado.

Pode-se considerar que os direitos humanos fundamentais são a base do arcabouço jurídico em um estado democrático de direito, de onde advém um conjunto de direitos e prerrogativas em uma perspectiva de igualdade, consubstanciados nos princípios constitucionais.

A presença desses direitos é logo observada no início da Constituição Federal de 1988, no título II, artigo $5^{\circ}$, sendo demonstrada ainda no parágrafo $1^{\circ}$, do mesmo artigo a sua efetividade: "as normas definidoras dos direitos e garantias fundamentais tem aplicação imediata".

Sobre o citado artigo, Sarlet (2009) ressalta:

Ao artigo 5o, § 1o, da Constituição de 1988 é possível atribuir, sem sombra de duvidas o mesmo sentido outorgado ao art. 18/1 da Constituição da Republica

\footnotetext{
${ }^{118}$ MORAES, A. de. Direitos humanos fundamentais. São Paulo: Atlas, 2006.
} 
Portuguesa e ao art. 1o, inc. III, da Lei Fundamental da Alemanha, o que, em ultima analise, significa- de acordo com a lição de Jorge Miranda- que cada ato (qualquer ato) dos poderes públicos devem tomar os direitos fundamentais como "baliza e referencial".Importante ainda, é a constatação de que o preceito em exame fundamenta uma vinculação isenta de lacunas dos órgãos e funções estatais aos direitos fundamentais, independentemente de forma jurídica mediante a qual são exercidas estas funções, razão pela qual- como assevera Gomes Canotilho- inexiste ato de entidade publica que seja livre dos direitos fundamentais. ${ }^{119}$

Sobre os direitos humanos fundamentais é unânime na doutrina brasileira a concordância do sentido que exprimem e os valores que protegem, pois são considerados cláusulas pétreas, imutáveis, frutos de uma evolução histórica, invioláveis, irrenunciáveis, absolutos, imprescritíveis, intransferíveis e indispensáveis a assegurar uma liberdade a todos.

Embora assim considerados, a efetividade advinda desses direitos pode ser compreendida pela materialização no mundo dos fatos, sendo preciso muitas vezes decorrer de uma conduta positiva, que exige uma posição mais ativa do Estado nas diversas esferas. O dicionário jurídico, escrito por Soibelman (1983), exprime nesse sentido o conceito de efetividade como:

Efetividade, derivado de efeitos, do latim effectivus, de efficere (executar, cumprir, satisfazer, acabar), indica a qualidade ou o caráter de tudo o que se mostra efetivo ou que está em atividade. Quer assim dizer o que está em vigência, está sendo cumprido ou está em atual exercício, ou seja, que está realizando os seus próprios efeitos. Opõe-se assim ao que está parado, ao que não tem efeito, ou não pode ser exercido ou executado. ${ }^{120}$

Corroborando ao exposto, Barroso ${ }^{121}$ (1996) retrata que a efetividade, na verdade, exprime um íntimo cerco entre o ser da realidade social e o dever ser normativo.

Nesse sentido, a efetividade da norma jurídica deve estar em sintonia com o fato social que ela se coloca a normatizar, principalmente as normas sociais, topograficamente localizadas no topo da Constituição Federal, que muitas vezes não conseguem ser plenamente efetivas.

No entanto, na atualidade o que se vivencia não é o que se apresenta acima, ao se perceberem sintomas de incongruência entre a realidade social e os textos fundamentais, que infelizmente, embora dada a sua importância, não atingem os limites razoáveis de efetividade, carecendo de força prática.

É sabido que o rol dos direitos fundamentais elencados na Carta Magna de 1988 é extenso, assim como algumas dificuldades para a efetivação dos mesmos. Tais dificuldades

\footnotetext{
${ }^{119}$ SARLET, I. W. A eficácia dos direitos fundamentais. 10a. ed. Porto Alegre: Livraria do Advogado, 2009.

${ }^{120}$ SOIBELMAN, L. Enciclopédia do advogado. 4. ed. Rio de Janeiro: Rio, 1983.

${ }^{121}$ BARROSO, L. R. Interpretação e aplicação da constituição: fundamentos de uma dogmática constitucional transformadora. São Paulo: Saraiva, 1996.
} 
por vezes não são enxergadas pelo Estado que, ao seu turno, deve possuir a capacidade de identificar as diferenças e particularidades dos cidadãos.

Nesse impasse, embora seja expressa a imediaticidade da aplicação dos direitos e garantias elencados no art. $5^{\circ}$ da Constituição Federal, a efetivação desses direitos, que nada mais objetiva além da verdadeira realização da justiça social, da correção das disparidades e condições dignas de vida, se concretiza por meio de prestações do Poder Público.

Enquanto não concretizados, tais direitos sofrem um déficit de efetividade, o que pode causar inúmeras ofensas aos ditames constitucionais, sendo na maioria dos casos justificados pela impossibilidade de atuação do Estado no retorno requerido.

No entanto o Estado deverá, indiscutivelmente, adentrar pela via obrigacional e aplicar a efetividade de tais direitos, dado que sem essa atuação não é possível viver dignamente. Caso constatada a omissão ou a realização da prestação de modo inadequada, podem ser exigidas judicialmente, devendo o poder judiciário analisar o caso e impor a realização de maneira adequada.

Chegados ao judiciário, os requerimentos de efetividade dos direitos fundamentais são discutidos por um viés acentuadamente político. Embora no final da lide seja declarada e confirmada sua possibilidade de efetuação, o judiciário muitas vezes desenvolve teorias que continuam a limitar a execução. Como exemplo, pode-se citar a teoria da reserva do possível explanada pelo autor Novelino 122 (2009), que alega que "a reserva do possível pode ser compreendida como limitação fática e jurídica oponível, ainda que de forma relativa, à realização dos direitos fundamentais, sobretudo os de cunho prestacional, pelo Estado”.

Nesse sentido, a justificativa da não concretização desses direitos tem-se resguardado, na sua maioria das vezes, na alegação de indisponibilidade financeira por parte do Estado e na inexistência de norma orçamentária que libere os recursos.

Hodiernamente, sabe-se que o orçamento governamental inclui metas, programas e objetivos relacionados a um determinado período de tempo e, ainda, que é composto de uma previsibilidade, o que acarreta em executar o que vai além do previsto ou não.

Visto isto, não basta a alegação de que não é possível atender as necessidades oriundas dos direitos humanos fundamentais. O Estado deve provar a sua inoperância nesse sentido diante da sua postura de provedor.

Como acentua o Ex-secretário Geral do Conselho Nacional de Justiça e Deputado Federal, Costa (2008):

${ }^{122}$ NOVELINO, M. Direito Constitucional. 3a. ed. São Paulo: Método, 2009. 
[...] no Brasil, um dos principais obstáculos para a promoção das garantias fundamentais é a ausência de regulamentação. Vários são os dispositivos constitucionais que completarão 20 anos sem nenhuma aplicação por causa de omissão legislativa; [...] Neste contexto, o Poder Judiciário tem destacado papel na garantia de direitos, ainda que estes não se encontrem devidamente regulamentados. ${ }^{123}$

Dependendo de uma regulamentação futura, essas normas se configuram de eficácia limitada, reduzida e mediata, incapazes de executar os interesses nelas previstos. Nesse âmbito, o não exercício de direitos, ocasionado pela ineficácia dessas normas, viola e impossibilita a realização das garantias constitucionais.

Além das normas de eficácia limitada, pode-se somar à conta o despreparo dos governantes em produzir as leis às legislações simbólicas, pelo fato de não trazerem uma saída para os rotineiros problemas da sociedade. Ou seja, tem-se programas, promessas políticas que não saem do papel e, quando saem, são leis sem aplicação, que acarretam nada mais do que o inchaço na legislação e a decepção da sociedade nos governantes.

Em detrimento disso, urge-se a imposição aos legisladores que permitam que tais normas produzam eficácia, pois se configura imprescindível a observância no trato da efetividade que deve existir, visto que os direitos humanos fundamentais são extremamente relevantes tanto na esfera social quanto na política, administrativa e jurídica. Eles proporcionam as principais garantias humanas que não apenas abrangem o direito nacional, como também o direito internacional.

Após elencados constitucionalmente, os direitos humanos fundamentais passam a possuir uma essência mínima que não pode ser violada pelas autoridades políticas e nem desrespeitada pelo legislador. Ou seja, os direitos humanos fundamentais, uma vez incorporados à Carta Magna, acarretam a responsabilidade obrigacional tanto do Poder Legislativo quanto da Administração Pública de respeitar sua essência e fazer valer a sua efetividade

Nesse ínterim, com o foco na análise abordada, percebe-se uma grave violação aos direitos humanos, que se consubstancia na inobservância dos direitos dos presos nas cadeias públicas do Brasil, bem como no desrespeito das normas internacionais que prelecionam no sentido de proteção da dignidade da pessoa humana, sendo suprimida assim a efetividade dessas normas.

${ }^{123}$ COSTA, F. D. de C. e. A Função Realizadora do Poder Judiciário e as Políticas Públicas do Brasil. In: Direitos sociais na Constituição de 1988: uma análise crítica vinte anos depois. São Paulo: Ltr, 2008. 
É notória a violação desses direitos, principalmente no que tange à mínima possibilidade de enquadramento digno, como se pode demonstrar em cadeias superlotadas, sujas, com a distribuição de refeições mínimas, presos cumprindo penas a mais do que o devido, um quadro generalizado de negligência estatal, o que não permite que o objetivo da ressocialização seja efetivo, agravando ainda mais a situação de violência no país.

Desse modo, a Teoria do Estado de Coisas Inconstitucional vem focar as atenções a esse quadro considerado inconstitucional, para que esses direitos preceituados normativamente na Constituição Federal e demais diplomas legais sejam realmente observados pelo Supremo Tribunal Federal e pelos demais poderes da república e que algo urgentemente seja realmente feito para mudar a realidade do sistema penitenciário brasileiro.

Posto isto, conclui-se que a efetividade dos direitos humanos fundamentais é mais do que imprescindível para que uma sociedade se desenvolva dignamente, para que se tenha sistemas institucionais que funcionem, prezando a justiça, assistência e proteção da dignidade humana.

\section{O ESTADO DE COISAS INCONSTITUCIONAL}

\subsection{Histórico}

De origem Colombiana, o instituto denominado de Estado de Coisas Inconstitucional (ECI) teve seu exórdio nas decisões da Corte Constitucional Colombiana (CCC), em 1997, ante ao estado de violações generalizadas e constantes de direitos humanos e fundamentais ocorridas naquele país.

A ideia de que tal instituto poderia atuar na correção da embaraçosa situação acometida na Colômbia se deu na Sentencia de Unificación (SU) 559, de 06/11/1997, quando um grupo de quarenta e cinco professores tiveram seus direitos previdenciários violados pelas autoridades locais.

Com o ocorrido, constatou-se que o inadimplemento da obrigação era geral, alcançando um número de pessoas bem maior ao que fora constatado na instauração das demandas. Ademais, observaram que a falha não advinha de um órgão único, mas sim que a situação tinha uma amplitude superior. 
Na oportunidade, a Corte Colombiana frisou a ocorrência de uma deficiência geral na educação, que tinha origem na forma desigual ao qual eram distribuídos os rendimentos dos profissionais de ensino, feito pelo governo federal.

Depois de reconhecida a gravidade do cenário local, a Corte Colombiana assegurou os direitos pleiteados dos demandados e ainda se dirigiu a resguardar de forma objetiva os direitos fundamentais violados.

Dessa forma, tomou a decisão de impor uma colaboração mútua entre os poderes, declarou o ECI, determinou que os territórios locais em situação idêntica reparassem em prazo razoável a discutida inconstitucionalidade e comunicou as autoridades competentes a esse caso para que tomassem as devidas providências necessárias.

Após esse caso, houveram outros dois mais merecedores do ECI, que são o caso de deslocamento de pessoas em razão da violência interna na Colômbia, decidido na Sentencia T - 025, de 2004, e o do sistema carcerário também do mesmo país, decidido na Sentencia de Tutela (T) - 153, de 1998.

Em ambos os casos, a Corte Colombiana utilizou métodos com o objetivo de remediar as situações não só das pessoas que pleitearam as demandas, mas também as de outras pessoas que de alguma forma se encontravam no mesmo quadro.

Ao contrário das primeiras sentenças declaratórias do ECI, nessa em particular foram constatados melhores resultados práticos que surtiram inúmeros efeitos positivos, visto que, em ato inédito, a Corte Colombiana decidiu supervisionar as implementações das políticas públicas cobradas aos responsáveis, o que fez total diferença nos resultados esperados.

Após os casos narrados, é sabido que o instituto já foi empregado em outras nove demandas na Corte Colombiana, sendo ainda utilizada pelas Cortes de alguns países latinoamericanos.

\subsection{Conceito}

O instituto, uma vez declarado, significa enunciar que determinada situação se acha em uma conjuntura insuportável decorrente de violações aos direitos fundamentais por atos comissivos e omissivos, muitas vezes realizados pelo poder público.

Visto isso, a sua finalidade se resume à ideia de uma implementação de soluções estruturais, orientadas a superar os lastimáveis panoramas de desrespeitos aos direitos das populações, propensas às omissões do poder estatal. 
Cabe ressaltar que a figura do litígio aqui comentado é caracterizada de forma estrutural, com um alcance amplo, por envolver complexas ordens de execução. Hernández ${ }^{124}$ (2003), sobre essa ideia, ressalta que diante da constatação da situação complexa, o tribunal supremo não deve se dirigir a deliberar sobre dilemas particulares, assegurando direitos singulares dos impetrantes, mas sim, deve socorrer a proporção objetiva dos direitos fundamentais afrontada.

Analisando as sentenças que declararam o ECI, pode-se perceber que esse estado deriva de três pressupostos: a) um cenário de forte desrespeito aos direitos fundamentais que atinge de forma generalizada e sistêmica um considerável número de pessoas; b) inexistência de parceria que promova medidas legislativas, judiciais, orçamentarias e administrativas que promovam mudanças estruturais; e c) escassez de políticas públicas expedidas pelos órgãos responsáveis em conjunto.

A própria corte colombiana, na Sentença T 025/2004, sistematiza seis pressupostos que estabelecem um Estado de Coisas Inconstitucional, são eles:

(1) Violação massiva e generalizada de vários direitos constitucionais, capaz de afetar um número significativo de pessoas;

(2) a prolongada omissão das autoridades no cumprimento de suas obrigações para garantir os direitos;

(3) a adoção de práticas inconstitucionais a gerar, por exemplo, a necessidade de sempre ter que se buscar a tutela judicial para a obtenção do direito;

(4) a não adoção de medidas legislativas, administrativas e orçamentárias necessárias para evitar a violação de direitos;

(5) a existência de um problema social cuja solução depende da intervenção de várias entidades, da adoção de um conjunto complexo e coordenado de ações e da disponibilização de recursos adicionais consideráveis;

(6) a possibilidade de um congestionamento do sistema judicial, caso ocorra uma procura massiva pela proteção jurídica. ${ }^{125}$

Ante ao exposto, percebe-se que o ECI resulta da estagnação do poder público em determinados fatos que necessitam de uma atuação efetiva para que direitos possam ser preservados.

Nessa fase, a atuação se funda não em uma exclusividade, mas sim em uma expansão objetiva dos direitos fundamentais, que por uma falha estrutural acaba alcançando inúmeras pessoas. Por causa dessa imensidão se faz necessário o trabalho em equipe das entidades, órgãos e poderes para que em conjunto busquem reduzir, superar ou acabar com os fatores que ocasionam o cenário da inconstitucionalidade.

\footnotetext{
${ }^{124}$ HERNÁNDEZ, C. I. V. La Garantía de la dimensión objetiva de los derechos fundamentales y labor del juez constitucional colombiano em sede de acción de tutela: el llamado "estado de cosas inconstitucional". Revista del Centro de Estudios Constitucionales, Universidad de Talca, Chile, ano 1, n. 1, 2003.

${ }^{125}$ REPÚBLICA DA COLÔMBIA. Corte Constitucional. Sentencia T-025/04: agência oficiosa en tutela Asociaciones de desplazados.
} 
Enfim, ao ser declarado, o Estado de Coisas Inconstitucional, antes de tudo, evidencia uma forma de demonstrar o fundo do problema, exprime a responsabilidade de cada órgão ou poder e exige ações que promovam uma solução.

\section{OS “ESTADOS DE COISAS INCONSTITUCIONAIS” NO BRASIL}

De uma forma mais complexa, voltada para a superação de sistemáticas situações gravosas a violações aos direitos fundamentais, inerentes a todos os cidadãos, o ECI chega ao Brasil propondo uma atuação em grupo, um trabalho associativo entre diversos poderes, órgãos, os quais irão atuar com o objetivo de cumprirem as metas acordadas, resolvendo inúmeros problemas de cunho estrutural.

Foi no julgamento do RE n. 592.581 e da ADPF n. 347 que o debate sobre o instituto de origem colombiana ganhou força. O Plenário da Suprema Corte brasileira decidiu, em 13 de agosto de 2015, que é possível que o Poder Judiciário imponha à administração pública obras de realização ou reformas urgentes aos presídios com o fim de garantir a integridade física e moral dos presos que ali pagam suas penas.

O Plenário da Suprema Corte ainda frisou não caber o emprego da cláusula da reserva do possível em consequência do vigor da essência fundamental do direito discutido. Sendo assim, julgou ser dever do Estado promover a defesa do mínimo existencial dos presos no que tange aos seus direitos fundamentais da integridade física e moral.

Assim, tal decisão pronunciada no julgamento do RE n. 592.581, interposto pelo Ministério Público do Rio Grande do Sul em contraposição ao Tribunal de Justiça local (TJ/RS), tendo como relator o Ministro Ricardo Lewandowski, cuja repercussão geral era o tema de n. 220, previa que independentemente de limites orçamentários, circunstâncias inversas ou choques entre outros direitos fundamentais, "a competência do Poder Judiciário para determinar ao Poder Executivo a realização de obras em estabelecimentos prisionais com o objetivo de assegurar a observância de direitos fundamentais dos presos". O STF assim decidiu:

Decisão: O Tribunal, por unanimidade e nos termos do voto do Relator, apreciando o tema 220 da repercussão geral, deu provimento ao recurso extraordinário para cassar o acórdão recorrido, a fim de que se mantenha a decisão proferida pelo juízo de primeiro grau. Ainda por unanimidade, o Tribunal assentou a seguinte tese: $\underline{E}$ lícito ao Judiciário impor à Administração Pública obrigação de fazer, consistente na promoção de medidas ou na execução de obras emergenciais em estabelecimentos prisionais para dar efetividade ao postulado da dignidade da pessoa humana e 
assegurar aos detentos o respeito à sua integridade física e moral, nos termos do que preceitua o art. 5o, XLIX, da Constituição Federal, não sendo oponível à decisão o argumento da reserva do possível nem o princípio da separação dos poderes.

Nesse caso em particular, ficou claramente explícita a posição do STF quando declarou ser lícita a imposição da obrigação de fazer, emanada pelo Judiciário ao Poder Executivo, diante da política penitenciária discutida, com o fim de proporcionar e resguardar os direitos inerentes aos detentos desse presídio em específico.

Além do caso citado acima, o STF, posteriormente, em julgamento da Medida Cautelar na ADPF n. 347, reiterou seu posicionamento proferindo determinações específicas a juízes e tribunais de todo o país, no que se refere ao quadro de violações de direitos fundamentais da população carcerária.

A jurisprudência brasileira sobre o reconhecimento do ECI ainda é restrita, assim como as produções doutrinárias acerca do tema que, na concepção de $\operatorname{Campos}^{126}$ (2015a), é identificada quando constatada a presença dos seguintes pressupostos:

a) quando constatado um cenário de deficiência massiva, estrutural e difusa de direitos essenciais que abala inúmeras pessoas;

b) a inexistência de gerência entre programas legislativos, administrativos, judiciais e orçamentários, que proporcionam uma ampla falha na estrutura do sistema de direitos, que acaba agravando ainda mais a situação; e

c) a sobrelevação desse quadro de violação impõe a emissão de remédios e obrigações dirigidas a diversos órgãos.

A partir daí, uma vez levada ao crivo do judiciário, é possível diagnosticar a situação do ECI em qualquer âmbito e esfera social. Isto é, esses pressupostos seriam o ponto de partida para a declaração do ECI, e o estopim para o estabelecimento de um diálogo institucional, entre todas as entidades envolvidas visando solucionar o problema.

A maioria desses pressupostos são consequências da má gestão dos recursos públicos por parte da administração, o que ocasiona inúmeros prejuízos gradativos, que afetam todas as áreas e entidades sociais.

No Brasil, os problemas sociais atuais não são de cunho isolado ou restrito, muito pelo contrário, são amplos e sua abrangência afeta a qualidade de vida da sociedade como um todo.

Em grau de emergência se acham os setores da saúde e o prisional, que há muito tempo não são acompanhados por eficientes políticas públicas, programas, projetos ou ações voltadas para o apoio institucional e o investimento necessário.

\footnotetext{
${ }^{126}$ CAMPOS, C. A. de A.. Da Inconstitucionalidade por Omissão ao Estado de Coisas Inconstitucional. Tese de Doutorado, UERJ, 2015a.
} 
Nesse cenário, o ECI, aplicado nas situações de emergências no Brasil, traça um diferencial político no primeiro momento, convidando os responsáveis a executarem suas obrigações estabelecidas na constituição. O que foi, até o presente momento, identificado e declarado em razão das péssimas condições que se encontram os presídios nacionais.

Descrevendo o quadro de inconstitucionalidade nos presídios brasileiros, o relator do RE n. 592.581, Ministro Ricardo Lewandowski, em seu voto assinala:

$\mathrm{O}$ fato é que a sujeição dos presos às condições até aqui descritas mostra, com clareza meridiana, que o Estado os está sujeitando a uma pena que ultrapassa a mera privação da liberdade prevista na sentença, porquanto acresce a ela um sofrimento físico, psicológico e moral, o qual, além de atentar contra toda a noção que se possa ter de respeito à dignidade humana, retira da sanção qualquer potencial de ressocialização. Sim, porque tais pessoas, muito embora submetidas à guarda e vigilância do Estado, devem merecer dele a necessária proteção, inclusive e especialmente contra violências perpetradas por parte de agentes carcerários e outros presos. O tratamento dispensado aos detentos no sistema prisional brasileiro, com toda a certeza, rompe com um dogma universal segundo o qual eles conservam todos os direitos não afetados pelo cerceamento de sua liberdade de ir e vir, garantia, de resto, expressa, com todas as letras, no art. 3o de nossa Lei de Execução Penal, confira-se: Ao condenado e ao internado serão assegurados todos os direitos não atingidos pela sentença ou pela lei. Parágrafo único. Não haverá qualquer distinção de natureza racial, social, religiosa ou política.

Em concordância com o relator, o Ministro Luís Roberto Barroso, em seu voto, expôs que esse é um velho tipo de problema estrutural ocasionado pela persistente omissão dos governantes, em destaque, do Poder Executivo, embora haja uma frequente atuação legislativa. Terminou seu voto afirmando que "eu acho que o Judiciário tem a legitimidade de intervir para superar um quadro crônico, histórico, atávico de omissão do Poder Executivo nessa matéria".

Segundo dados do Levantamento Nacional de Informações Penitenciárias (Infopen) até julho de 2014, o Brasil possuía uma população carcerária de 622.202 presos, configurando o quarto país no mundo com a maior população carcerária. Podendo esse número ter sido acrescido, visto o descaso de atenção voltado a esse tema.

Retratada a situação, pode-se afirmar que a vida carcerária dos presos brasileiros, em estado de verdadeiro abandono, se identifica em partes com o caso colombiano, principalmente quando o estado de inconstitucionalidade decorre da inexecução adequada dos meios materiais capazes e eficazes de alcançar os resultados queridos na Constituição. 
Para a proteção dos preceitos fundamentais da Constituição, o legislador reservou um instrumento processual específico, a ADPF, e embora não tenha pontuado o seu procedimento ou eficácia, estabeleceu que o Supremo Tribunal Federal é o competente para analisá-la quando proposta. Assim é previsto no artigo 102, § $1^{\circ}$, da $\mathrm{CF}^{127}$ : "A arguição de descumprimento de preceito fundamental, decorrente desta Constituição, será apreciada pelo Supremo Tribunal Federal, na forma da lei”.

Alguns autores avaliam de forma positiva a ausência da real definição do conteúdo substancial objeto da ação de Arguição de Descumprimento de Preceito Fundamental. Nesse sentido, Mandelli Júnior ${ }^{128}$ (2003) denota que a carência dessa previsão proporciona à jurisprudência uma melhor flexibilidade, no que tange à permissão de mudanças quanto à consistência dos valores da norma constitucional, acomodando com deslize as transformações na comunidade, implementando um critério constitucional de interpretação evolutiva, reservando um espaço para que o preceito constitucional seja tratado como fundamental, como também para que não seja considerado, visto que os mesmos transcorrem do Estado na sua história constitucional.

Diante dessas observações, pode-se conferir ao STF a responsabilidade de assentar o conteúdo de preceito fundamental conforme a evolução jurisprudencial brasileira. Dessa forma proclamou o Ministro Néri na primeira ADPF (n.1) ${ }^{129}$ proposta: “compete ao STF o juízo acerca do que se há de compreender, no sistema constitucional brasileiro, como preceito fundamental".

Dentre tantas outras reclamadas ao Supremo, recentemente, em maio de 2015, veio a discussão a ADPF 347/DF, pelo Partido Socialismo e Liberdade (PSOL), defendendo a tese do Estado de Coisas Inconstitucional em face do sistema prisional brasileiro. Em síntese, o partido requereu ao STF a declaração de que a atual situação do sistema penitenciário brasileiro viola gravemente os direitos e preceitos fundamentais garantidos pela Carta Magna de 1988, e, na ocasião, em específico, os direitos fundamentais inerentes aos presos.

Nessa razão, foi pleiteado pelo partido que a Corte Suprema determinasse à União e aos Estados uma série de medidas que objetivassem sanear as lesões e violações ocorridas dentro do sistema. Contudo, até o presente momento, não se julgou em definitivo o mérito da ação proposta pelo partido socialista, mas o relator da ação, o Ministro Marco Aurélio, deferiu, parcialmente, a medida liminar determinando aos juízes e tribunais que:

\footnotetext{
${ }^{127}$ BRASIL. Constituição Federal de 1988. Promulgada em 5 de outubro de 1988.

${ }^{128}$ MANDELLI JÚNIOR, R. M.. Arguição de descumprimento de preceito fundamental: instrumento de proteção dos direitos fundamentais e da Constituição. São Paulo: Revista dos Tribunais, 2003.

${ }^{129}$ ADPF 1-QO. Julgamento em 03/02/00, DJ de 07/11/03.
} 
a) caso determinem ou mantenham a prisão provisória, registrem expressamente o motivo pelo qual não foi aplicado as medidas alternativas a privação de liberdade, elencadas no art. 319 do Código de Processo Penal;

b) observem os preceitos pactuados e as convenções seguidas pelo Brasil, que determinam a realização em ate 90 dias de audiências de custódia, proporcionando a presença do apenado a autoridade judiciária no período de no máximo 24 horas do momento da prisão; e

c) considerem o cenário de horror que se encontra o sistema prisional quando forem conceder cautelares, no procedimento de execução da penal e quando da aplicação da pena.

Aos juízes ainda foi estabelecido que, quando emanadas as penas, sempre que possível, optem em aplicar as penas alternativas à prisão, visto que em muitos casos o regime de reclusão é executado de modo muito mais severo que o admitido.

À União foi designada a liberação dos valores reunidos no Fundo Penitenciário Nacional para ser empregado ao objetivo pelo qual foi constituído, coibindo-se de efetuar novas despesas.

Percebe-se um reconhecimento por parte do Plenário que verdadeiramente há uma violação massiva aos direitos fundamentais dos presos, que estão suportando penas desumanas e cruéis. No entanto, há uma morosidade em julgar definitivamente a matéria discutida, o que ocasiona um retardo ainda maior em resolver o problema da inconstitucionalidade nos presídios brasileiros.

Além do mais, é sabido por toda a sociedade que os cárceres do Brasil não servem nem para a ressocialização dos detentos, muito pelo contrário, estão servindo de escola do crime, onde muitos entram como pequenos infratores e saem verdadeiros monstros. Como prova da ineficiência do sistema penitenciário brasileiro temos as altas taxas de reincidência detectadas nos últimos anos.

O responsável direto pela aplicação da pena, o Estado, mostra-se indiferente com o princípio da humanidade. Dentre os seus preceitos, está a defesa pela proibição de maustratos, tortura e penais cruéis a condenados sob a tutela estatal.

Bitencourt ${ }^{130}$ (2002), ao decorrer sobre esse princípio, expõe que a inibição de tortura, de penas cruéis e infames e de maus tratos nos procedimentos policiais são pressupostos do princípio da humanidade. Além disso, tal princípio impõe a obrigação de o Estado possuir na

\footnotetext{
${ }^{130}$ BITENCOURT, C. R. Manual de direito penal: parte geral. 7. ed., São Paulo, Saraiva, 2002.
} 
sua estrutura carcerária os recursos que impeçam a dessocialização e degradação dos apenados.

Infelizmente, é consternado o estado de falência em que se encontra o sistema penitenciário brasileiro. As denúncias de gravíssimas violações a diversos direitos fundamentais, que são pronunciadas e até materializadas em propostas apresentadas ao crivo do Judiciário, com o objetivo de se obter um desentranhamento do estado de caos identificado, não deixam concluirmos de outra forma.

A doutrina lamenta o padecimento da proteção efetiva dos direitos fundamentais dos presos por parte do Estado, e reconhece o Estado de Coisas Inconstitucional que o país vive. Nesse entendimento, Campos (2015a) afirma:

\begin{abstract}
Trata-se de graves deficiências e violações de direitos que se fazem presentes em todas as unidades da Federação brasileira e podem ser imputadas à responsabilidade dos três poderes: Legislativo, Executivo e Judiciário. Significa dizer: são problemas tanto de formulação e implementação de políticas públicas quanto de aplicação da lei penal.

$[\ldots]$

Por certo que, não se trata de inércia de uma única autoridade pública, nem de uma única unidade federativa, e sim do funcionamento deficiente do Estado como um todo que tem resultado na violação desses direitos. Os poderes, órgãos e entidades federais e estaduais, em conjunto vem se mantendo incapazes e manifestado falta de vontade política em buscar superar ou reduzir o quadro objetivo de inconstitucionalidade. Falta sensibilidade legislativa quanto ao tema da criminalização das drogas, razão maior das prisões. O próprio Judiciário tem contribuído com o excesso de prisões provisórias, mostrando falta de critérios adequados para tanto. Falta estrutura de apoio judiciário aos presos. Trata-se, em suma, de mau funcionamento estrutural e histórico do Estado como fator do primeiro pressuposto, o da violação massiva de direitos. ${ }^{131}$
\end{abstract}

Importante ressaltar que, dentre as violações já pontuadas, restam também desrespeitados o Pacto Internacional dos Direitos Civis e Políticos, a Convenção contra a Tortura, como também a Lei de Execução Penal Brasileira.

Sobre o afastamento do "estado de inconstitucionalidade" requerido na ação, o relator, Ministro Marco Aurélio, diz ser somente provável caso ocorra uma mudança significativa na forma de atuação do Poder Público. Registra ainda que há um conjunto de problemas a serem resolvidos, que englobam tanto a implementação e formulação de políticas públicas quanto a interpretação da Lei de Execução Penal.

Sustentando a incumbência da Corte Suprema, o Ministro, em seu voto na ADPF 347, ressalta que diante desse quadro é preciso:

\footnotetext{
${ }^{131}$ CAMPOS, C. A. de A.. Da Inconstitucionalidade por Omissão ao Estado de Coisas Inconstitucional. Tese de Doutorado, UERJ, 2015a.
} 
Retirar as autoridades públicas do estado de letargia, provocar a formulação de novas políticas públicas, aumentar a deliberação política e social sobre a matéria e monitorar o sucesso da implementação das providências escolhidas, assegurando a efetividade prática das soluções propostas.

Nesse ínterim, o ministro confirma que a Corte Suprema tem parcela de responsabilidade e que deve atuar para combater o estado inconstitucional, provocando as demais autoridades a formularem deliberações nesse sentido, embora não afirme como poderão assegurar a efetividade que tanto se espera.

Já a Procuradoria-Geral da República (PGR), em seu parecer, apesar de reconhecer a grave magnitude da situação penitenciária brasileira e a importância dos pedidos contidos na ADPF no 347, alertou para a generalidade e a abrangência das medidas cautelares pleiteadas.

Ademais, vale evidenciar que nas duas recentes ADPFs analisadas nesta pesquisa, sobre o tema da inconstitucionalidade voltado ao instituto colombiano do ECI, o Supremo aprofunda e consolida uma orientação já anteriormente efetivada na ADPF 45, em direção à interferência na seara do Poder Executivo, especificamente nas suas competências administrativas, com o fulcro de afastar o quadro de calamidade detectado, neste caso, no sistema carcerário brasileiro.

Por fim, percebe-se que a Suprema Corte não se nega a receber casos emblemáticos como o discutido na pesquisa. Mostra-se com isso a sua atenção aos problemas sociais com que em parte também tem responsabilidade. No entanto, embora atenda ao pleito, decide genericamente. Tais decisões são muitas vezes ineficazes, o que não se espera na prática, pois, possuindo a obrigação de ser guardião da Constituição e garantidor das políticas governamentais, deve acima de tudo prestigiar o texto maior e zelar pelos direitos previstos.

Destarte, nota-se um efeito simbólico das decisões, como as demais que são conduzidas ao crivo da Suprema Corte para a sua análise, permanecendo a situação sem efeito até a presente data, como no caso apresentado.

\section{CONSIDERAÇÕES FINAIS}

Percebe-se que a existência de Estados de Coisas Inconstitucionais é fato notório em muitas nações do mundo, não sendo diferente no Brasil, em vários setores da sociedade, podendo-se citar exemplos como questões que envolvam: a saúde pública na maioria dos estados e municípios, o sistema carcerário, a violência, a educação precária, dentre outros. 
No decorrer desse trabalho, ressaltou-se que esses quadros de violação aos direitos humanos constitucionalmente previstos no país são agravados por pura inoperabilidade de alguns poderes, permitindo um estado de verdadeiro caos social quando omissões e burocracias institucionais e políticas impedem a efetividade e aplicação das ações de monitoramento e gestão pública.

Visto isto, apesar da sua imaturidade em solo nacional, a técnica utilizada para declarar um estado inconstitucional se mostra plenamente aplicável quando detectadas suas características e requisitos, como, pois, foram identificadas e descritas na ADPF N. 347/DF, cujo atual condão é combater o estado falacioso do sistema prisional brasileiro.

Em sua atuação pode-se considerar que a prática, uma vez utilizada, proporciona um maior controle a todos os incumbidos pela tarefa de reestruturar o quadro negativo, já que a solução de um atrito de enormes proporções exige um diálogo institucional entre todos os poderes envolvidos e responsáveis pela situação inconstitucional. Ou seja, a possibilidade de controle coletivo das tarefas direcionadas a cada instituição individualmente pode resultar em uma plena eficiência nas atividades direcionadas, sendo isto mais um ponto positivo da teoria.

Por fim, apesar das diversas diferenças entre as cortes, STF e a CCC, a declaração do Estado de Coisas Inconstitucional e a sua posterior prática pode desenvolver um efetivo modo de trabalhar nas falhas estruturais e nas ordens de monitoramento das mesmas. O que pode até permitir estudos e análises de um novo modo de restruturação ainda mais efetivo, por meio de alternativas modernas, práticas e menos ortodoxas.

Diante de todo o exposto, por mais que se critique a atuação proativa do judiciário e embora seja o correto dizer que as iniciativas das políticas públicas devem ser do Poder Executivo e Legislativo, não é coerente afirmar que a ausência delas não possibilite o exercício regular por outro poder. Isto é, o Supremo não pode se manter neutro de braços cruzados, visto que essa omissão não deve ser obstáculo para a fruição e efetividade dos direitos fundamentais.

\section{REFERÊNCIAS}

BARROSO, Luís Roberto. Interpretação e aplicação da constituição: fundamentos de uma dogmática constitucional transformadora. São Paulo: Saraiva, 1996.

BITENCOURT, Cezar Roberto. Manual de direito penal: parte geral. 7. ed., São Paulo, Saraiva, 2002. 
BRASIL. Constituição Federal de 1988. Promulgada em 5 de outubro de 1988. Disponível em <http://www.planalto.gov.br/ccivil_03/constituicao/constituição.htm>. Acesso em: 14 out. 2017.

CAMPOS, Carlos Alexandre de Azevedo. Da Inconstitucionalidade por Omissão ao Estado de Coisas Inconstitucional. Tese de Doutorado, UERJ, 2015a.

COSTA, Flávio Divino de Castro e. A Função Realizadora do Poder Judiciário e as Políticas Públicas do Brasil. In: Direitos sociais na Constituição de 1988: uma análise crítica vinte anos depois. São Paulo: Ltr, 2008.

HERNÁNDEZ, Clara Inés Vargas. La Garantía de la dimensión objetiva de los derechos fundamentales y labor del juez constitucional colombiano em sede de acción de tutela: el llamado "estado de cosas inconstitucional". Revista del Centro de Estudios Constitucionales, Universidad de Talca, Chile, ano 1, n. 1, 2003.

MANDELLI JÚNIOR, Roberto Mendes. Arguição de descumprimento de preceito fundamental: instrumento de proteção dos direitos fundamentais e da Constituição. São Paulo: Revista dos Tribunais, 2003.

MORAES, Alexandre de. Direitos humanos fundamentais. São Paulo: Atlas, 2006.

NOVELINO, Marcelo. Direito Constitucional. 3a. ed. São Paulo: Método, 2009.

REPÚBLICA DA COLÔMBIA. Corte Constitucional. Sentencia T-025/04: agência oficiosa en tutela - Asociaciones de desplazados. Disponível em: <http://www.corteconstitucional.gov.co/relatoria/2004/t-025-04.htm>. Acesso em: 21 fev. 2017.

SARLET, Ingo Wolfgang. A eficácia dos direitos fundamentais. 10a. ed. Porto Alegre: Livraria do Advogado, 2009.

SOIBELMAN, Leib. Enciclopédia do advogado. 4. ed. Rio de Janeiro: Rio, 1983. 


\begin{abstract}
The technique created by the Colombian Constitutional Court, called "Unconstitutional State of Things", a new and not much studied subject, is used when there is a scene of vast violation of fundamental rights, caused by the constant and ongoing inactivity or ineptitude of the public authorities in altering the current context, in such a way that only structural changes in the exercise of Public Power and the performance of a diversity of authorities can transform the unconstitutional situation. With the Unconstitutional State of Things, a new way to solve structural problems will be formed, allowing the uttering of decisions that create mechanisms to open deliberation channels, aiming to control the organization and execution of public policies in a participatory manner, compromised in general with the protection of the rights that were broken. Therefore, this research proposes an analysis of the theory, the requirements and parameters to apply it to the Brazilian reality in situations of violations and unconstitutionality to the fundamental rights covered by Federal Constitution. This work was realized through a qualitative bibliographic method, by a systematic research in books, articles, journals and websites that approach the subject, in addition to the current Legal Order. Regarding the scientific methodology of analysis, we use the theoretical-descriptive methods, as well as a dialectical analysis of the problem presented.
\end{abstract}

Keywords: Fundamental Rights. Unconstitutional State of Things. ADPF 347. Supreme Federal Court. 